\title{
REFLEXÕES SOBRE A EDUCAÇÃO AMBIENTAL QUANTO A FORMAÇÃO DO PROFESSOR PEDAGOGO NO CONTEXTO DE PANDEMIA: CONTRIBUIÇÕES PARA O FORTALECIMENTO DA JUSTIÇA SOCIAL E AMBIENTAL
}

\author{
Elocir Aparecida Corrêa Pires ${ }^{1}$ \\ Eliane Picão da Silva Costa ${ }^{2}$ \\ Fabiane Pacanhela-Borges ${ }^{3}$ \\ Ana Lúcia Olivo Rosas Moreira ${ }^{4}$
}

Resumo: $O$ presente trabalho apresenta algumas reflexões em relação à pandemia do coronavírus (COVID- 19) em nível mundial e nacional e analisa as ações que estão sendo tomadas pelos governantes para a mitigação desse problema. Considerando que a preocupação ambiental é um tema transversal, o objetivo dessa investigação foi refletir sobre a formação do educador ambiental no processo formativo do Pedagogo, por meio de uma análise nas Diretrizes Curriculares do curso de Pedagogia e do Projeto Político Pedagógico (PPP) de uma Instituição pública de Ensino Superior, localizada no oeste do Paraná. Dessa forma, observou-se que muitos desafios emergem neste cenário da pandemia quanto à formação e a prática docente do pedagogo.

Palavras-chave: Formação de Professores; Ensino Fundamental dos Anos Iniciais; Coronavírus; Interdisciplinaridade.

\footnotetext{
1 Universidade Estadual de Maringá-UEM. E-mail: lupetrie10@hotmail.com. Link para o Lattes: http://lattes.cnpq.br/6291984361344107

2 Universidade Estadual de Maringá-UEM. E-mail: lilipcd@hotmail.com. Link para o Lattes: http://lattes.cnpq.br/3013403140821637

3 Universidade Estadual de Maringá-UEM. E-mail: borgesfabiane@hotmail.com. Link para o Lattes: http://lattes.cnpq.br/7222304238849639

4 Universidade Estadual de Maringá-UEM. E-mail: alormoreira@gmail.com. Link para o Lattes: http://lattes.cnpq.br/3227131664005073
} 
Abstract: The present work shows some reflections in relation to the coronavirus pandemic (COVID-19) at a global and national level and analyzes the actions that are being taken by the government to mitigate this problem. Considering that environmental concern is a transversal theme, the objective of this investigation was to reflect on the formation of the environmental educator in the pedagogical training process, through an analysis in the Curricular Guidelines of the Pedagogy course and the Pedagogical Political Project (PPP) of a Public institution of Higher Education, located in western Paraná. In this way, other challenges emerge in this scenario of the pandemic regarding the training and teaching practice of the pedagogue.

Keywords: Teachers Formation; Elementary School in the Initial Years; Coronavirus; Interdisciplinarity.

\section{Introdução}

A sociedade de forma geral vem passando por inúmeras transformações no decorrer do tempo, culminando em mudanças profundas em vários setores: social, econômico, político, ambiental, dentre outros. Historicamente, a chamada crise social e ambiental tem se intensificado, tomando proporções cada vez mais destrutivas e catastróficas. Os padrões de produção e desenvolvimento estabelecidos pelo neoliberalismo caracterizaram o modelo de apropriação dos recursos naturais pelo homem. Como defendido por Carvalho (2014), o homem não se constitui como um ser alheio a natureza, mas sim como parte integrante do meio natural, pois sua ação pode modificar a essência natural do meio ambiente, seja para preservá-la, cultivá-la ou destruíla.

Nos últimos meses, a população mundial vem sofrendo com a pandemia de um vírus que causa infecções respiratórias. Com os primeiros casos registrados na China, esse agente viral, o coronavírus, provoca a doença chamada de COVID-19. No Brasil, ainda no final do mês de julho, foram contabilizadas mais de 80 mil mortes causadas pelo vírus, segundo o Ministério da Saúde (BRASIL, 2020). Ultrapassando a taxa de mil mortes diárias, as expectativas de conter a doença não são nada animadoras. Levando em conta esses números, provavelmente logo passaremos de 100 mil óbitos. Assim, esse contexto pandêmico traz um cenário preocupante para vários setores da sociedade, agravando ainda mais a crise social e ambiental.

O desenvolvimento da tecnologia e da ciência, atualmente, está acontecendo de maneira muito rápida, o que resulta em algumas vantagens inegáveis para o ser humano. Entretanto, apresenta, também, efeitos negativos difíceis de serem enfrentados, principalmente em países com grande contingente de população que vive em contextos de vulnerabilidades e desigualdades sociais, como é o caso do Brasil. Por conta disso, uma avaliação crítica sobre os processos envolvidos no seu desenvolvimento e 
produção é indispensável, principalmente quanto às questões ambientais e de justiça social.

Dessa forma, defendemos que há a necessidade de uma compreensão dos fatores problemáticos que reveste a relação entre a sociedade e o meio ambiente, tendo em vista um melhor entendimento da nossa interação com a natureza de uma maneira mais harmônica e respeitosa. Nesse sentido, é necessário repensar nosso modelo de desenvolvimento para a manutenção da qualidade de vida no planeta e da nossa própria existência.

Nessa direção, a educação exerce um papel fundamental no desenvolvimento integral da pessoa, visando à preparação para o exercício pleno da cidadania, envolvendo a dignidade humana como um dos princípios fundamentais. Essa questão aponta para a necessidade de busca de elementos que possibilitem a mitigação das desigualdades sociais, vista como uma questão de justiça social, o que implica a necessidade de formar professores preocupados com tais condições e que possam realizar, a partir de seu profissionalismo, mudanças no indivíduo e na sociedade como um todo.

Dessa forma, defendemos a necessidade da EA no processo educativo da Educação Básica, essencial para o desenvolvimento crítico e consciente das crianças, diante do panorama ambiental contemporâneo em que vivemos. Para que ações pedagógicas que envolvam a EA passem a estar presentes no contexto da sala de aula, é necessário olhar para a formação docente, principalmente dos professores que atuam na base, ou seja, nos primeiros anos de escolarização das crianças.

Assim, entendemos que essa realidade exige discussões complementares a respeito da Educação Ambiental Crítica no cotidiano escolar, pois é necessário que o professor tenha algum contato com a temática em certo momento de sua formação profissional. Nesse sentido, buscamos responder ao seguinte questionamento: em que medida o curso de Pedagogia possibilita a formação de um educador ambiental?

\section{Pandemia analisando o cenário brasileiro}

Vivemos tempos conturbados de uma pandemia e, no contexto brasileiro, podemos observar seu impacto em diversos setores desde as relações humanas com desdobramentos na área da saúde, da economia, da política e também da educação.

Diferentemente do que aconteceu na Europa, como na Alemanha, por exemplo, que entendendo a gravidade da pandemia, logo no início, buscou unir a população em ações de isolamento social, de apoio e acesso aos serviços de saúde no combate ao vírus, no Brasil a realidade é outra. O vírus foi tratado pela autoridade presidencial como uma "gripezinha", a ponto de participar de uma manifestação, pedindo a abertura do comércio e das escolas, favorecendo a exposição da população ao contágio do vírus. Nesse viés, o que vemos é a 
falta de liderança e alinhamento no discurso do presidente e de seus ministros da saúde.

Dessa forma, a crise, que era sanitária, transformou-se numa crise política. Essa postura deixou o Brasil no epicentro de mortes e contaminados pela COVID-19, que acabou sendo visto como algo preocupante pelos órgãos de saúde e pela Organização Mundial de Saúde - OMS. Incapaz de dar uma proposta ao enfrentamento da doença, o governo mergulha o país numa crise sem precedentes. Como conseqüência disso, nossa imagem no meio internacional passou a ser vista com preocupação, abalando a credibilidade e a reputação do país.

A indiferença da nossa autoridade presidencial não passa só pela pandemia, mas pela educação, em especial pela universidade pública, que vem sendo fortemente atacada em sua autonomia. Além disso, ainda há o desprezo pela preservação dos recursos naturais, ataques constantes à Amazônia, à comunidade indígena e ribeirinha, resultando em um grande descaso com a justiça social e ambiental.

Segundo Ataíde e Borja (2017, p. 62) o conceito de justiça social "[...] surge da articulação de um conjunto de dimensões no campo social, do acesso a bens e serviços, entre outros, objeto de discussão de muitas disciplinas".

Para os autores supramencionados, quando falamos em justiça social implica pensar:

[...] no impacto socioambiental que representa o acesso a bens e serviços de um cidadão. É refletir sobre os mecanismos que a prática individual constrói e fomenta na sociedade. Além disso, é ter responsabilidade pelas desigualdades que 0 acesso de um indivíduo a certos bens e serviços provoca no corpo social e, principalmente, em seus representantes mais frágeis, aqueles indivíduos que especificamente tiveram seus lugares iniciais em situações de baixo ou nenhum acesso aos sistemas de valorização profissional e benefícios oriundos da capacidade produtiva e inventiva da humanidade. (ATAIDE; BORJA, 2017, p.63)

Segundo Gamarnikow (2013) "[...] a justiça social é também profundamente influenciada pelo contexto social e pelas condições históricas da localidade social na qual ela emerge". No contexto brasileiro, mais do que nunca, precisamos fortalecer o engajamento político por justiça social. Ainda de acordo com Gamarnikow (2013), o Brasil preserva uma histórica tradição de engajamento em prol da justiça social como: o Movimento dos Trabalhadores Sem Terra, o MST, a teologia da libertação, as lutas dos povos indígenas, que busca preservar suas culturas e de ambientalistas comprometidos com a preservação das florestas tropicais do Brasil. 
O cenário atual, de modo geral, fundamentado no modelo de desenvolvimento produtivo neoliberal, tem gerado grandes perdas sociais e ambientais. Fortalecendo as desigualdades, o que vale é a luta competitiva em que o progresso de todos os sistemas está interligado ao crescimento econômico e tecnológico. Tais características, que nos tornam humanos, são descartadas e, assim, o sentimento de solidariedade e de cooperação não fazem mais parte das nossas reflexões. Nesse viés, as relações sociais são destruídas, nos tornando cegos diante dos desdobramentos que essa realidade causa como a fome, a pobreza, a má distribuição de renda, o desemprego, a violência, entre outras mazelas que afetam a sociedade e o meio ambiente. Essa realidade, com ênfase exclusivamente no aspecto econômico, tem agravado cada vez mais as desigualdades sociais e a crise ambiental (VASCONCELOS et. al, 2014).

De acordo com Kliksberg (2003 apud VASCONCELOS et.al, 2014, p.248), as soluções para os problemas sociais apresentam certos obstáculos que estão "[...] associados à forma equivocada de entender e formular políticas econômicas e sociais, gerando mitos e falácias que impedem uma ação mais efetiva". Dessa forma, afirmamos que os problemas, atualmente enfrentados no contexto brasileiro, impedem que acreditemos em uma possibilidade de melhoria de vida. Apesar da comunicação de providências tomadas, o que prevalece fortalecido é a ineficiência de quaisquer alternativas para a resolução de problemas sociais. Isso significa que as conformidades às injustiças social e ambiental permitem que as pessoas atuem como alheias ao contexto presenciado por todos (VASCONCELOS et. al, 2014, p. 248).

Nesse viés de desigualdade, Vilches e Gil-Pérez (2007) apontam alguns problemas ambientais relacionados ao modelo econômico vigente e que afetam a sociedade como um todo. Trata-se de fatores problemáticos que repercutem na contaminação, na degradação dos ecossistemas, na exaustão de recursos naturais, nas mudanças climáticas, na perda de diversidade biológica, entre outros.

É necessário que o debate sobre justiça social e ambiental, que acontece nos movimentos sociais, também possa alcançar os alunos no ambiente escolar, para que as ações desses movimentos tenham visibilidades entre os alunos e, assim, a luta por uma educação de qualidade e por justiça social e ambiental se torne universal.

Sforni (2006) considera que a escola tem o papel de qualificar 0 indivíduo para as condições impostas pela sociedade, sejam elas imediatas ou futuras. Somando a esta afirmação, Krasilchik (2000) focaliza que as escolas refletem as mudanças que ocorrem na sociedade, sejam elas políticas, econômicas, sociais e/ou culturais, além de identificar a educação básica como o nível de ensino mais afetado por tais influências.

Dessa forma, o modelo de educação, pautado na concepção democrática, necessita preparar o aluno para tomada de decisões, além de 
formar um sujeito social que possa intervir criticamente na sua realidade e transformá-la. Nesse sentido, o fortalecimento das lutas por justiça social depende cada vez mais de pessoas que tenham informações fundamentadas, e com condições de questionar e argumentar em defesa de decisões básicas que dizem respeito aos interesses individuais e coletivos.

Precisamos possibilitar que o conhecimento científico e tecnológico seja acessível para toda a população e não restritos aos pequenos grupos. Reconhecemos que existem grupos menos favorecidos em questões sociais, econômicas e ambientais, os quais não podemos limitar o acesso ao conhecimento e aos recursos tecnológicos públicos.

\section{Educação ambiental no curso de pedagogia}

Nos últimos anos, observa-se, nas escolas, um aumento nas mobilizações sobre a necessidade de inclusões e orientações coerentes com as premissas da sustentabilidade socioambiental. Essa conduta corresponde ao entendimento de que o desenvolvimento do homem está intrinsicamente ligado à relação estabelecida com o meio em que vive. Diante disso, o modo muitas vezes despreocupado da ação humana sobre a natureza traz problemáticas ambientais quase que irreversíveis para o planeta, denotando do comportamento humano a necessidade de uma nova postura e mudança de atitude sobre o contexto social e ambiental.

Como destacado por Santos (2010), ao contrário dos animais, o ser humano, devido a sua condição social ao longo do desenvolvimento histórico, acumulou uma grande bagagem de conhecimentos intelectual e cultural, mediante ações de descobertas, observações e mediações sobre a natureza. Essa condição humana necessita proporcionar a todos o direito de acesso e compartilhamento do rol de conhecimento. Nessa perspectiva, no processo educacional, é importante que cada membro que compõe a sociedade tenha a possibilidade de ter acesso ao conhecimento acumulado e, também, daquele em desenvolvimento. Assim, o que se almeja é que, por meio da educação, cada sujeito possa compartilhar os conhecimentos desenvolvidos pelas gerações antecedentes, além de recriar seus próprios conhecimentos, visando o desenvolvimento intelectual autônomo e emancipado do ser humano (SANTOS, 2010).

Diante do exposto, entendendo que o Curso de Pedagogia é responsável pela formação de professores que irão atuar nos anos iniciais da educação básica (base da formação dos sujeitos), torna-se relevante investigar de que forma a educação ambiental se apresenta nas orientações curriculares que fundamentam a formação desse profissional. Como determinado na legislação, "[...] a dimensão ambiental deve constar nos currículos de formação de professores, em todos os níveis e em todas as disciplinas" (BRASIL, 1999, art.11). 
Tais postulações traduzem a necessidade dos cursos de formação de professores orientarem sobre a importância da educação ambiental, proporcionando reflexões críticas sobre as questões socioambientais. São nessas circunstâncias que vemos, no curso de Pedagogia, um ambiente propício à formação de educadores ambientais, capazes de intervir em ações compromissadas com a dimensão socioambiental, que contribua para a transformação da consciência ambiental dos nossos futuros alunos.

A partir dessas reflexões, a presente pesquisa busca evidências sobre orientações contidas nos documentos oficiais, considerando a educação ambiental na formação do professor Pedagogo.

Como observado nos Parâmetros Curriculares Nacionais (PCN) (BRASIL, 1997), uma das finalidades da Educação ambiental é a mudança de comportamento, visando à preservação da natureza, como é exposto no documento:

[...] a principal função do trabalho com o tema Meio Ambiente é contribuir para a formação de cidadãos conscientes, aptos para decidirem e atuarem na realidade socioambiental de um modo comprometido com a vida, com o bem-estar de cada um e da sociedade, local e global. Para isso é necessário que, mais do que informações e conceitos, a escola se proponha a trabalhar com atitudes, com formação de valores, com o ensino e a aprendizagem de habilidades e procedimentos. E esse é um grande desafio para a educação. Comportamentos "ambientalmente corretos" serão aprendidos na prática do diaa-dia na escola: gestos de solidariedade, hábitos de higiene pessoal e dos diversos ambientes, participação em pequenas negociações podem ser exemplos disso (BRASIL, 1997, p. 25).

Nessa mesma direção, a Lei Federal 9.795, de 27 de abril de 1999, ressalta em seu artigo $1^{\circ}$ que a educação ambiental se constitui por processos nos quais cada indivíduo, juntamente com a coletividade "[...] constroem valores sociais, conhecimentos, habilidades, atitudes e competências voltadas para a conservação do meio ambiente, bem de uso comum do povo, essencial à sadia qualidade de vida e sua sustentabilidade" (BRASIL, 1999).

A Lei de Diretrizes e Bases da Educação Nacional determina que a educação ambiental precisa ser considerada de forma inter e transdisciplinar, sendo contemplada com os demais conteúdos curriculares de todos os níveis educacionais, sem ficar restrita a uma única disciplina. Além disso, há necessidade de engajamento em projetos integrados com a comunidade escolar, com a família, com associações públicas e privadas e com a sociedade em geral, para que promovam ações que estimulem hábitos de respeito ao meio ambiente, capazes de assegurar uma nova consciência ambiental. 
$\mathrm{Na}$ mesma direção, as Diretrizes Curriculares para o Curso de Pedagogia destacam a importância da inserção da educação ambiental na formação inicial do pedagogo, ao reiterar que "[...] os processos de ensinar e de aprender dão-se em meios ambiental-ecológicos, em duplo sentido, isto é, tanto professoras(es) como alunas(os) ensinam e aprendem, uns com os outros" (BRASIL, 2006, p. 8). Dessa forma, a "Organização Curricular do curso de Pedagogia" demanda estar pautada na [...] preservação do meio ambiente articuladamente à da saúde e à vida, além de outras questões de relevância local, regional, nacional e até mesmo internacional" (BRASIL, 2006, p. 10).

Nesse sentido, destacando a orientação de uma educação interdisciplinar, a DCN enfatiza que o licenciando em Pedagogia:

Art. 3 [...] trabalhará com um repertório de informações e habilidades composto por pluralidade de conhecimentos teóricos e práticos, cuja consolidação será proporcionada no exercício da profissão, fundamentando-se em princípios de interdisciplinaridade, contextualização, democratização, pertinência e relevância social, ética e sensibilidade afetiva e estética (BRASIL, 2006, p. 1).

De acordo Morin (2003), o ensino pautado no retalhamento das disciplinas impede a aprendizagem global e integral dos estudantes. Dessa forma, destaca-se a importância de desenvolver a educação ambiental de forma contextualizada, que dialogue com todas as áreas do saber, proporcionando, ao aluno, que é sujeito da aprendizagem, o conhecimento complexo. Tais recomendações são fortalecidas, porque, muitas vezes, as aspirações humanísticas passam a fundamentar-se em orientações curriculares pragmáticas, por meio de visões técnicas, fragmentadas e resistentes às mudanças.

Para Fazenda (2004), a interdisciplinaridade é uma categoria de ação do fazer reflexivo, do acontecer entre duas ou mais pessoas e objetos. É a relação sujeito-objeto ou entre sujeitos, na qual é possível a integração e a unidade do conhecimento, a partir de zonas de permeabilidade de diálogos e a leitura de diferentes mundos.

Analisando o Projeto Político Pedagógico (PPP), do curso de Pedagogia de uma universidade pública no oeste do Paraná, podemos observar que a reestruturação curricular organizada para ser implementada, a partir de 2017, traz definições que visam atender a política de Educação Ambiental. A primeira delas é a Lei oㅡ 9.795, de 1999, o decreto oㅡ 4.201, de 2002 (BRASIL, 1999), bem como o cumprimento da Deliberação CEE/PR no, de 2013, do Estado do Paraná, que estabelece normativas para a Educação Ambiental no sistema de ensino nas instituições de educação básica e superior (PARANÁ, 2013). Nesse viés, o PPP orienta que, para o cumprimento da 
legislação, as ementas das disciplinas "Teoria e prática do ensino de Ciências" e "Sociologia da Educação" foram modificadas, tendo em vista a inclusão de conteúdos específicos sobre EA (Quadro 1).

Quadro1: Componentes curriculares que atendem a EA na formação do Pedagogo

\begin{tabular}{|c|c|c|}
\hline Disciplinas & Ementa & $\begin{array}{c}\text { Carga } \\
\text { horária }\end{array}$ \\
\hline $\begin{array}{l}\text { Sociologia } \\
\text { da Educação }\end{array}$ & $\begin{array}{l}\text { Estudo da relação educação e sociedade: entendidos como } \\
\text { um processo dinâmico de transformação e reprodução das } \\
\text { relações sociais; } \\
\text { Análise das relações entre educação e movimentos sociais: } \\
\text { movimentos sociais negros; movimentos sociais indígenas; } \\
\text { movimentos sociais do meio ambiente; movimentos sociais do } \\
\text { campo; movimentos sociais de gênero e sexual. }\end{array}$ & 126hs \\
\hline $\begin{array}{lr}\text { Teoria } & e \\
\text { Prática } & d o \\
\text { Ensino } & \text { de } \\
\text { Ciências } & \end{array}$ & $\begin{array}{l}\text { Estudo das relações entre o homem e natureza, mediadas } \\
\text { pelo trabalho como origem da ciência, tecnologia e sociedade. } \\
\text { Concepções de Ensino de Ciências da Natureza e Educação } \\
\text { Ambiental e suas implicações curriculares e pedagógicas: } \\
\text { objetivos, conteúdos, metodologias, linguagens e processos } \\
\text { de apropriação. }\end{array}$ & $68 \mathrm{hs}$ \\
\hline
\end{tabular}

Fonte: adaptado do PPP do curso de Pedagogia.

O documento menciona ainda as atividades extracurriculares de extensão e a estrutura de coleta e destinação de resíduos que comporta o campus, que fazem parte do dia a dia dos acadêmicos, contribuindo para a sua formação.

Cabe destacar que, apesar de constar no PPP a presença da educação ambiental em duas disciplinas, isso não impede que seja abordada em outros componentes curriculares de forma interdisciplinar, pois, como bem colocado na literatura, a EA se constitui de forma transversal a todas as áreas do conhecimento.

O maior empenho para modificar essa visão faz parte da contextualização das disciplinas no registro pedagógico da escola, chamado de Projeto Político Pedagógico. A solução se dá ao permitir que os docentes compreendam o mundo atual e a complexidade do ser humano.

Como destacado por Santos (2010), a educação ambiental pautada em ações críticas reflexivas busca determinar mudanças sociais e culturais que estimulem a convivência coletiva e contribuam para um melhor equilíbrio entre a relação do ser humano com a natureza.

Neste sentido, as Diretrizes Curriculares Nacionais (DCNs), enfatizam a necessidade da formação interdisciplinar do professor pedagogo, para que em sua prática pedagógica, ele busque promover a contextualização, preparando o sujeito para as exigências da sociedade. 


\section{O educador ambiental e o desafio da educação à distância}

O Conselho Nacional de Educação (CNE) normatizou, a partir da Medida Provisória n`943, a flexibilização do cumprimento dos 200 dias letivos, desde que mantida a carga horária mínima anual de cada etapa definida pela Lei de Diretrizes e Bases da Educação Nacional - LDB (BRASIL, 2020). Logo após, o CNE orientou, a partir do parecer 05/20, de 28 de abril do ano 2020, que os sistemas de ensino estaduais e municipais poderiam, em situações emergenciais, autorizar a realização de atividades não presenciais (BRASIL, 2020b).

Em meio ao caos da pandemia, a modalidade de ensino à distância se tornou essencial para que as atividades de ensino se mantivessem durante 0 período. Assim, as escolas, tanto do setor público quanto privado, buscam o enfrentamento dos desafios sociais e educacionais que encontramos no ensino à distância. Diante dessa situação, um dos fatores para que essa modalidade de ensino seja implantada é o uso de recursos tecnológicos, especialmente por meio da Tecnologia Digital de Informações e Comunicação (TDIC).

Podemos afirmar, de acordo com nossa experiência e relato de colegas, que muitos de nós, professores, não tínhamos formação e também não estávamos habituados às atividades online e vídeo aulas. Mas a nova condição de ensino possibilitou, a todos, uma nova experiência, estabelecendo inovações nas redes culturais, redefinindo compreensões de mundo que o atual cenário exige e contribui para o desenvolvimento de práticas alternativas e da construção de novos saberes.

Assim como os professores, os alunos também enfrentam dificuldades no acesso às atividades e aulas online. Os desafios se diferenciam de acordo com cada realidade familiar, que em sua maioria é a indisponibilidade de equipamentos como computador, celular, rede de internet, entre outros fatores que impactam negativamente na possibilidade de aprendizagem dos alunos.

Dados do Instituto Brasileiro de Geografia e Estatística (IBGE) coletados pela Pesquisa Nacional por Amostras de Domicílios Contínua (PENAD), referente ao quarto trimestre de 2018, mostram o percentual de acesso dos domicílios brasileiros às TDIC. Em relação à 2017, para o ano de 2018, o percentual de utilização da internet nos domicílios subiu de $74 \%$ para $79,1 \%$, considerando que mais de $20 \%$ das residências não possuem acesso à internet. Na zona rural, a situação é mais crítica. De 2017 para 2018, o índice passou de $41,0 \%$ para $49,2 \%$, ou seja, observa-se que mais de $50,0 \%$ das famílias rurais brasileiras não têm acesso à internet (IBGE, 2020).

As condições de acesso às tecnologias é um fator limitante na utilização de recursos tecnológicos, principalmente para as populações desfavorecidas. De certa forma, as tecnologias digitais transformam a maneira como interagimos, nos comunicamos e vivemos em sociedade. Por outro lado, é preciso garantir que essa tecnologia esteja disponível para todos.

revista brasileira educação ambiental 
O gráfico 1 mostra o rendimento médio per capita dos domicílios por Grandes Regiões, segundo utilização da internet $-4^{\circ}$ trimestre de 2018.

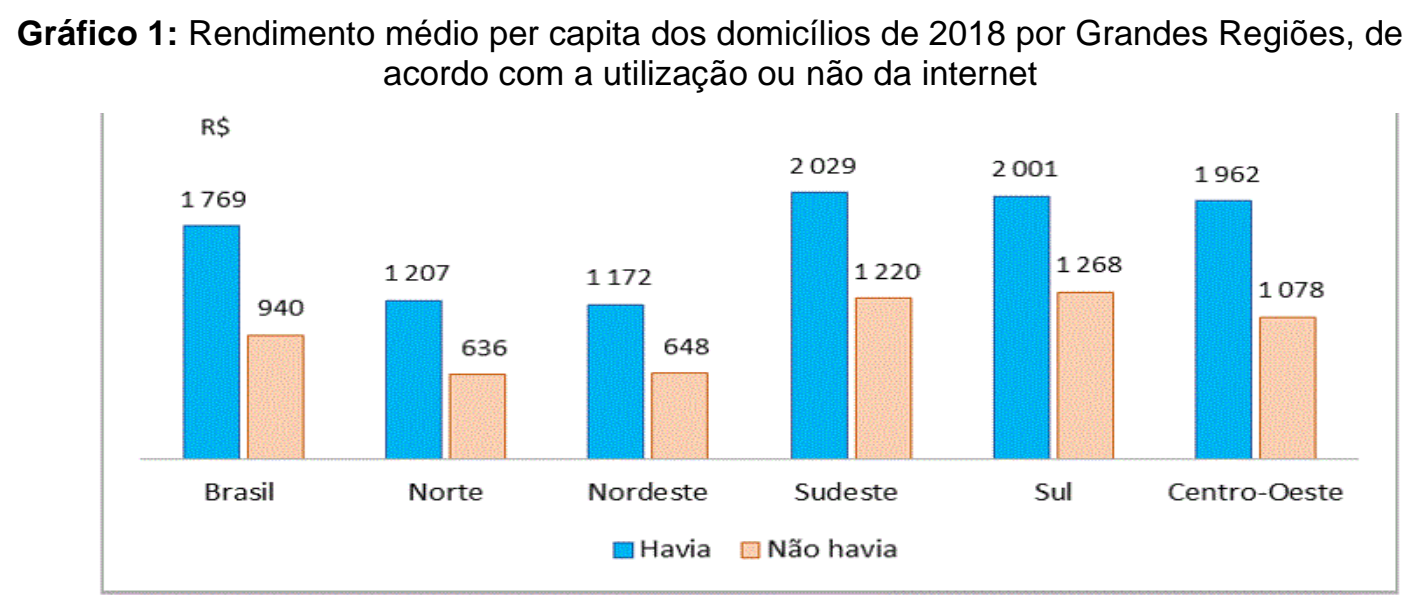

Fonte: IBGE (2020)

Essas diferenças ressaltam a desigualdade social existente em nosso país, contrariando o que definimos por justiça social, como o acesso a bens e serviços para todos. Layrargues (2009) afirma que a desigualdade é multifacetada e pode se apresentar em inúmeras manifestações sociais, porém reforça que a política educacional é uma das imperativas para o combate à desigualdade.

Nesse sentido, a autoformação dos professores nesse período de pandemia é crucial para que se dê continuidade no ensino que, até então, acontecia de forma presencial e agora acontece de forma remota. Para Martins (2015), a autoformação promove o processo "aprender a aprender". Assim, fundamentar a educação no profissional que aprende se mostrou de extrema relevância nesse período, tornando-se uma condição básica para a nova cultura do ensino remoto em todas as áreas e níveis de educação.

Segundo Molon (2003), a relação eu - outro permite a compreensão dos processos de apropriação, objetivação e subjetivação, porém não depende da presença corpórea ou física em um mesmo ambiente. Para a autora, a mediação ocorre por meio dos signos, da palavra, da semiótica e dos instrumentos de mediação, o que torna a educação remota viável. Maia (2015) considera que a apropriação de ideias e objetividades não se completam ao final da formação acadêmica, mas se estendem por toda a experiência.

Nesse sentido, a proposta da formação de educadores, abordada por Vygotsky (1995), garante que ocorra um processo que valorize a experiência do sujeito e assegure a reflexão, a reelaboração de ações e a superação de visões, ou seja, a partir da tomada de consciência de novas informações e 
saberes, novos conhecimentos são desenvolvidos, além de auxiliarem na ampliação da capacidade de reflexão da ação.

Nóvoa (1997) afirma que o trabalho focado na experiência do professor é essencial em tempos de mudanças e crise, como está o atual cenário mundial. Segundo Martins (2015) as crises e mudanças podem ser enfrentadas por professores que tiveram uma formação reflexiva, pois esses profissionais assumem a responsabilidade de seu próprio desenvolvimento como docente que é promovido juntamente com o desenvolvimento pessoal.

$O$ educador ambiental, nesse período, deve manter-se reflexivo em relação às suas ações para que os desafios que a realidade educacional causa nesse momento sejam superados. Para Libâneo (2006, p. 76), a prática pedagógica "trata-se de conteúdos vivos, atualizados e articulados criticamente com as realidades sociais presentes". Assim, compreendemos a importância de reconhecer a nova situação e seus aspectos sociais, culturais e psicológicos, valorizando o significado humano das relações sociais.

\section{Conclusões}

Com a incerteza da retomada das atividades presenciais e convictos de que a pandemia trará mudanças na realidade escolar, consideramos a autoformação essencial nesse período, para que os professores sejam preparados e flexíveis ao que se espera de uma nova normalidade no cotidiano escolar. Assim, os docentes, de todos os níveis, devem procurar cursos na modalidade à distância, além de aperfeiçoamentos, recursos tecnológicos e compartilhar dos conhecimentos adquiridos para que possa divulgar e auxiliar outros professores em suas aulas.

Nesse sentido, acreditamos que os professores busquem cada vez mais refletir sobre sua prática em todos os aspectos, procurando uma formação reflexiva. Tais profissionais assumem a responsabilidade de seu próprio desenvolvimento como docente, que ocorre em conjunto com o desenvolvimento pessoal, fortalecido por uma atuação promotora de inovações pedagógicas, sem deixar de inserir as diversas temáticas presentes no contexto da COVID-19 e em contextos de tempos futuros.

É essencial repensar a democratização da educação, possibilitando um ensino, não só visando a questão da utilização das tecnologias, mas também ao que se refere em possibilitar o acesso à informação e aos recursos tecnológicos para pessoas mais carentes, que não dispõem dessas tecnologias ou de uma com melhor qualidade.

Esse é, também, o momento para refletir que não devemos dar importância aos valores econômicos como sendo único e central, em que o valor do ser humano não esteja apenas na obsessão pelo consumo de coisas, mas sim na cultura que nos humaniza e que nos torna cidadãos críticos e participativos para o bem comum. 


\section{Referências}

ATAIDE, G. V. T. L; BORJA, P. C. Justiça social e ambiental em saneamento básico: um olhar sobre experiências de planejamento municipais. Ambiente \& Sociedade, São Paulo, v. XX, n. 3, p. 61-80, jul.-set. 2017. Disponível em: < https://www.scielo.br/pdf/asoc/v20n3/pt_1809-4422-asoc-20-03-00061.pdf > Acesso em: 17 jun. 2020.

BRASIL. Lei de Diretrizes e Bases da Educação Nacional. Lei n. 9.394 de 20 de dezembro de 1996.

Parâmetros Curriculares Nacionais: meio ambiente e saúde. Brasília: DF: Secretaria de Educação Fundamental, 1997.

Política Nacional de Educação Ambiental. Lei Federal n 9.795 de 27 de abril de 1999.

. Resolução n.1, 15.5.2006. Diário Oficial da União, n.92, seção 1, p.11- 12, 16 maio 2006.

- Ministério da Saúde (BR). Concelho Nacional de Saúde. COVID19 no Brasil. [Internet]. Brasília: Ministério da Saúde; 2020. Disponível em: <http://susanalitico.saude.gov.br/\#/dashboard/> Acesso em: 29 jul. 2020.

. Medida Provisória n934 de 01 de abril de 2020. Estabelece normas excepcionais sobre o ano letivo da educação básica e do ensino superior decorrentes das medidas para enfrentamento da situação de emergência de saúde publica de que trata a Lei no13.979, de 6 de fevereiro de 2020. Diário Oficial da União. Brasília, DF, 01 abril de 2020. Seção 1- Extra, p.1. Disponível em: < http://www.in.gov.br/en/web/dou/-/medida-provisoria-n-934-de-1-de-abrilde-2020-250710591> Acesso em: 16 jun. 2020.

BRASILb. Ministério da Educação. Conselho Nacional de Educação. Parecer no 9/2020, 28 abr de 2020. Reorganização do Calendário Escolar e da possibilidade de cômputo de atividades não presenciais para fins de cumprimento da carga horária mínima anual, em razão da Pandemia da COVID-19. Diário Oficial da União, Brasília, DF. 28 abr de 2020. Seção 1, p.32. Disponível em: $<$ http://portal.mec.gov.br/index.php?option=com_docman\&view=download\&alia $\mathrm{s}=145011$-pcp005-20\&category_slug=marco-2020-pdf\&ltemid=30192> Acesso em: 16 jun de 2020.

CARVALHO, S. A. Justiça social e ambiental: um instrumento de consolidação à sustentabilidade. Revista Eletrônica Direito e Política, Programa de PósGraduação Stricto Sensu em Ciência Jurídica da UNIVALI, Itajaí, v.9, n.2, 2o quadrimestre de 2014. Disponível em: <www.univali.br/direitoepolitica> Acesso em: 24 maio. 2020. 
FAZENDA, I. C. A. Colocação feita em sala de aula, sistematizada em registros de memória em 24 mar. 2004. Pontifícia Universidade Católica, São Paulo, 2004.

GAMARNIKOW, E. Educação, (in)justiça social e direitos humanos: combatendo desigualdades na globalização turbocapitalista. Revista Brasileira de Educação, Rio de Janeiro, v. 18, n. 52, jan.-mar. 2013. Disponível em: <https://www.scielo.br/pdf/rbedu/v18n52/11.pdf> Acesso em: 25 maio. 2020.

INSTITUTO BRASILEIRO DE GEOGRAFIA (IBGE). PNAD Contínua TIC 2018: Internet chega a 79,1\% dos domicílios do país.2020. Disponível em: $<$ https://agenciadenoticias.ibge.gov.br/agencia-sala-de-imprensa/2013-agenciade-noticias/releases/27515-pnad-continua-tic-2018-internet-chega-a-79-1-dosdomicilios-do-pais> Acesso em: 15 junho. 2020.

KRASILCHIK, M. Reformas e realidade: o caso do ensino de Ciências. São Paulo em Persperctiva, v.14, n.1, p. 85-93, 2000. Disponível em: < https://www.scielo.br/pdf/spp/v14n1/9805.pdf> Acesso em: 06 junho. 2020.

LAYRARGUES, P. P. (org.). Repensar a educação ambiental: um olhar crítico. São Paulo: Cortez, 2009.

LIBÂNEO, J. C. Democratização da escola pública: a pedagogia críticosocial dos conteúdos. 21ed. São Paulo: Edições Loyola, 2006.

MAIA, J. S. S. Educação ambiental crítica e formação de professores. Curitiba: Appris, 2015.

MARTINS, L. M. A formação social da personalidade do professor: um enfoque vigotskiano. 2.ed. Campinas: Autores Associados, 2015

MOLON, S.I. Subjetividade e constituição do sujeito em Vygostsky. Petrópolis: Vozes, 2003.

NÓVOA, A. Formação de professores e profissão docente. In: NÓVOA, A. (Coord.). Os professores e sua formação. Lisboa: Dom Quixote, 1997. Disponível

em:

<http://repositorio.ul.pt/bitstream/10451/4758/1/FPPD_A_Novoa.pdf.> Acesso em:04 junho de 2020.

MORIN, Edgar. A cabeça bem-feita: repensar a reforma, reformar o pensamento. 8. ed. Rio de Janeiro: Bertrand Brasil, 2003.

PARANÁ, CEE. Deliberação no 04/13, de 12 de novembro de 2013. Estabelece as Normas Estaduais para a Educação Ambiental. Sistema Estadual de Ensino do Paraná. 2013. Disponível em: <http://www.cee.pr.gov.br/arquivos/File/pdf/Deliberacoes/2013/deliberacao_04_ 13.pdf $>$. Acesso em 17 jun de 2020

SANTOS, J. R. Ética e natureza: o papel da educação meio ambiente construção de um novo olhar. Revista Eletrônica do Mestrado em Educação. 
v. 25, p. 218-232. jul./dez. 2010. Disponível em: < https://periodicos.furg.br/remea/article/view/3510> Acesso em: 07 jun. 2020.

SFORNI, M. S. F. Aprendizagem conceitual e organização do ensino: contribuições da teoria da atividade. Cascavel: Junqueira e Marin, 2006.

VASCONCELOS, E. R.; FREITAS, N. M. S.; FERREIRA, D. T.; VALENTE, J. A. S.; FREITAS, N. M. S. Educar para a justiça social e ambiental: que questões pensar no contexto do ensino e da formação de professores de ciências? Revista Brasileira de Pesquisa em Educação em Ciências, v. 14, n. 2, 2014. Disponível em:

https://periodicos.ufmg.br/index.php/rbpec/article/view/4365/2931>Acesso em: 25 maio. 2020.

VILCHES, A.; GIL PÉREZ, D. Emergencia planetaria: necesidad de un planteamiento global. Educatio Siglo XXI, n. 25, p. 19-50, 2007. Disponível em: < https://revistas.um.es/educatio/article/view/716/746> Acesso em: 25 jun. 2020.

VYGOTSKY, L. S. Obras escogidas. Tomo III. Madri: Visor, 1995. 